effects. The present report involving the use of synthetic ACTH confirms previous studies in Japan, using natural ACTH (Hrachovy RA et al. High-dose, long-duration versus low-dose, short-duration corticotropin therapy for infantile spasms. I Pediatr 1994;124:803-806; Fois A et al. Brain Dev 1987;9:82-84; and Ito M et al. Pediatr Neurol 1990;6:240-244). Proponents of high-dose ACTH include Snead OC et al. Neurology 1989;39:1027-1031; and Bobele GB, Bodensteiner JB. Neurologic Clinics Aug 1990, Philadelphia, WB Saunders. See Progress in Pediatric Neurology I, PNB Publ, 1991;pp30-34, for further discussion of ACTH in treatment of infantile spasms.

\title{
SHORT-TERM MORTALITY AFTER FIRST EPILEPTIC SEIZURE
}

The short-term mortality in a prospective study of a cohort of 804 patients, aged 2 months to 94 years, with a first seizure was determined at the University Hospitals of Bordeaux and Montpellier, France. At 1-year follow-up, 149 patients had died as compared to 16 expected deaths. None who died had idiopathic seizures. Mortality was increased in patients with remote symptomatic seizures, provoked seizures, and seizures due to progressive neurologic disease. Only $6 \%$ of deaths were seizure-related. The majority $(64 \%)$ were caused by the underlying pathology, 20\% an unrelated condition, and $9 \%$ unknown factors. (Loiseau J, Picot M-C, Loiseau P. Short-term mortality after a first epileptic seizure: a populationbased study. Epilepsia Oct 1999;40:1388-1392). (Reprints: Dr P Loiseau, 4 allee de Carabin, 33460 Arsac, Bordeaux, France).

COMMENT. Early mortality following a first epileptic seizure is rarely related to the seizure per se and is determined by the underlying etiology, especially those with underlying pathology and with seizures caused by progressive neurologic disease, or by unrelated conditions. Provoked seizures must be distinguished from unprovoked seizures, when determining risk factors for a poor prognosis in epilepsy.

\section{ANTICONVULSANT DRUGS}

\section{ADVERSE EFFECTS OF TOPIRAMATE}

The effectiveness and safety of topiramate in 87 children with intractable epilepsy treated at three Canadian Centers were evaluated at the IWK-Grace Health Centre, Halifax, NS, Canada. Seizure reduction was >90\% in $8(9 \%), 50-90 \%$ in 21 (24\%), and $<50 \%$ in $54(62 \%)$ of patients. Treatment was discontinued in $36(41 \%)$ because of adverse events, especially cognitive dulling, in 27 (31\%). The occurrence of cognitive dulling was not related to the rate of dose escalation and final dose level. (Dooley JM, Camfield PR, Smith E, Langevin P, Ronen G. Topiramate in intractable childhood onset epilepsy - a cautionary note. Can I Neurol Sci Nov 1999;26:271-273). (Reprints: Dr JM Dooley, Neurology Division, IWK-Grace Health Centre, 5850 University Ave, Halifax, Nova Scotia, Canada B3J 3G9).

COMMENT. Cognitive dysfunction can be a serious and frequent side effect of topiramate treatment of intractable epilepsy in children.

\section{AED-ASSOCIATED MAJOR CONGENITAL ABNORMALITIES}

The risk of major congenital abnormalities associated with maternal antiepileptic drug (AED) therapy during the first trimester of pregnancy was determined in 1,411 children born between 1972 and 1992 in four provinces in the Netherlands, and compared to 2000 nonepileptic matched controls. The risk 
increased with the number of AEDs used: $1.5 \%$ in untreated controls, $3.3 \%$ with 1 AED, $4.7 \%$ with $2,4.4 \%$ with 3 , and $8 \%$ with exposure to $4+$ AEDs. Risk of major congenital abnormalities in the offspring was significantly increased for 1) carbamazepine and valproate monotherapy, with a significant dose-response relationship for valproate; 2) phenobarbital, when combined with caffeine; and 3) several polytherapy regimens, including clonazepam with other AEDs, carbamazepine and valproate combination, and phenobarbital with caffeine combined with other AEDs. Valproate monotherapy is especially associated with spina bifida and hypospadias. Phenytoin monotherapy was not associated with increased risk. (Samren EB, van Duijn CM, Christiaens GCML, Hofman A, Lindhout D. Antiepileptic drug regimens and major congenital abnormalities in the offspring. Ann Neurol Nov 1999;46:739-746). (Respond: Prof Lindhout, MGC-Department of Clinical Genetics, Erasmus University Rotterdam, PO Box 1738, NL-3000 DR Rotterdam, The Netherlands).

COMMENT. Polytherapy with AEDs is more often associated with an increased risk of major congenital abnormalities than monotherapy, and the risks are higher. Combinations of benzodiazepines with valproate and carbamazepine are especially teratogenic, and should be avoided during pregnancy. Caffeine, usually considered relatively harmless, raises the risk of malformations if taken in combination with phenobarbital during the first trimester. The ingestion of caffeine containing drinks might also pose a risk factor.

\section{CEREBELLAR ATAXIA}

\section{CEREBELLAR ATAXIA WITH CELIAC DISEASE}

A case of clinical and electrophysiologic improvement following a glutenfree diet in a 34-year-old man with a 7-year history of slowly progressive ataxia is reported from the University of Napoli Federico II, Napoli, Italy. Neurologic exam revealed gait ataxia, positive Romberg's sign, nystagmus, dysarthria, dysmetria, and mild spasticity. Brain MRI showed vermis atrophy, and nerve conduction studies showed a sensory neuropathy. Vitamin E and B12 serum levels were normal. Antigliadin (AGAs) and antiendomysium antibodies (EMAs) were abnormal, and small bowel biopsy revealed total villous atrophy, crypt hyperplasia, and increased lymphocytes in the lamina propria. These signs of subclinical celiac disease had returned to normal when repeated 1 year later, following gluten-free diet. Neurological findings also improved after 2 years of dietary treatment. (Pellecchia MT, Scala R, Perretti A et al. Cerebellar ataxia associated with subclinical celiac disease responding to gluten-free diet. Neurology Oct 1999;53:1606-1608). (Reprints: Dr Paolo Barone, Clinica Neurologica, Ed 17, Department of Neurological Sciences, Via S Pansini 5, 80131 Napoli, Italy).

COMMENT. Cerebellar ataxia with classic celiac disease does not respond to the gluten-free diet, whereas the patient with subclinical celiac disease shows a remarkable improvement in neurologic signs and resolution of the villous atrophy.

Multiple cerebellar infarctions in a 7-year-old Japanese boy without cerebellar signs is reported from Shiga University, Hikone, Japan. (Ohno M, Suzuki A, Suzuki K et al. Cerebellar infarction in a young boy. Acta Paediatr Oct 1999;88:1162-1164). The child presented with uveitis, of undetermined cause. 